\section{Estudo \\ CoDebate}

em Testão

Planejamento
Revista Estudo \& Debate, Lajeado, v. 26, n. 3, 2019. ISSN 1983-036X

DOI: http://dx.doi.org/10.22410/issn.1983-036X.v26i3a2019.2105

\title{
INDICAÇÃO DE ALOCAÇÃO DOS CUSTOS EM PROJETOS DE DESPOLUIÇÃO: UMA ANÁLISE DAS BACIAS HIDROGRÁFICAS DOS RIOS IPOJUCA E CAPIBARIBE
}

\author{
Gabriela Carine Brito Costa ${ }^{1}$, Monaliza De Oliveira Ferreira ${ }^{2}$
}

\begin{abstract}
Resumo: $\mathrm{O}$ presente trabalho tem como objetivo analisar a alocação dos custos em projetos de despoluição para o Rio Ipojuca e o Rio Capibaribe entre os municípios com sede urbana nas respectivas bacias hidrográficas. Isto se faz necessário devido os altos custos ambientais, sociais e econômicos causados pela poluição destes rios, uma vez que, além de aumentar os custos de tratamento da água, há o impacto de externalidades negativas para os municípios com sede nestas bacias hídricas. Para a análise, foi utilizado o Valor de Shapley, que é derivado da teoria dos jogos cooperativos. A variável determinante para alocar os custos em projetos de despoluiçáo foi o volume de esgoto não tratado referido à água consumida que cada município despejou nas respectivas bacias hidrográficas ao longo do ano de 2015. A análise realizada a partir dos dados obtidos pelo Valor de Shapley indicou que a dinâmica demográfica dos municípios é o fator que mais influi na poluição dos rios, devido principalmente ao crescimento demográfico desordenado, que dificulta a prestação dos serviços de saneamento. Resultado intrigante, especialmente para lugares com maior efetivo de lavanderias de jeans. Por outro lado, talvez a informalidade e quantidade de facçôes (pequenos fabricos realizados em casa) possam explicar melhor este resultado.
\end{abstract}

Palavras-chave: Economia do Meio Ambiente. Recursos Hídricos. Teoria dos Jogos. Valor de Shapley.

\section{INDICATION OF ALLOCATION OF COSTS IN THE DECONTAMINATION PROJECTS: AN ANALYSIS OF THE HYDROGRAPHIC BACIES OF THE RIVERS IPOJUCA AND CAPIBARIBE}

\begin{abstract}
The objective of this work is to analyze the allocation of costs in the decontamination projects of the Ipojuca River and the Capibaribe River between the municipalities with urban headquarters in the respective hydrographic basins. This is necessary due to the high environmental, social and economic costs caused by the pollution of these rivers, since besides increasing the costs of water treatment, there is the impact of negative
\end{abstract}

1 Mestranda do Programa de Pós-Graduação em Economia - PPGECON. Universidade Federal de Pernambuco/Campus do Agreste. E-mail: gabrielabrito8@gmail.com.

2 Docente Pesquisadora do Programa de Pós-Graduação em Economia - PPGECON. Universidade Federal de Pernambuco/Campus do Agreste. E-mail: monalizaoferreira@gmail.com. 
externalities for the municipalities with headquarters in these water basins. For the analysis, we used the Shapley Value, which is derived from the theory of cooperative games. The determinant variable to allocate the costs in decontamination projects was the volume of untreated sewage referred to the water consumed that each municipality poured in the respective hydrographic basins throughout the year of 2015 . The analysis obtained from the Shapley value indicated that the demographic dynamics of the municipalities is the factor that most influences the politics of the rivers, mainly due to the disorderly demographic growth, that makes difficult the provision of sanitation services. An intriguing result, especially for places with more effective denim laundries. On the other hand, perhaps the informality and quantity of factions (small homemade factories) can better explain this result.

Keywords: Environmental Economy. Hydric Resources. Game Theory. Shapley Value.

\section{Introduçáo}

O Polo de Confecçóes do Agreste, localizado no Estado de Pernambuco, é um importante centro comercial do qual fazem parte mais de 30 cidades localizadas na Região, mas a maior parte da produção concentra-se em três cidades: Caruaru, Santa Cruz do Capibaribe e Toritama, que acabaram se tornando as de maior destaque econômico do Polo. Há poucos estudos econômicos sobre o Arranjo Produtivo, mas destaque-se o do SEBRAE (2013), que realizou um Estudo Econômico descrevendo quantitativamente o Polo de Confecçōes do Agreste, e de Oliveira (2012, p.1), que caracteriza o Polo de Confecçóes do Agreste como sendo "um aglomerado de iniciativas produtivas e comerciais relacionadas ao setor de confecçóes."

A importância deste setor para a economia local é bastante significativa. Os dados da Relaçáo Anual de Informaçóes Sociais - RAIS do Ministério do Trabalho e Emprego (BRASIL/MTE/RAIS, 2015) revelam que em 2015 haviam 21.107 vínculos empregatícios ativos no setor de confecçáo de artigos do vestuário e acessórios no Estado de Pernambuco. Destes, 5.609 em Caruaru, 4.317 em Santa Cruz do Capibaribe e 1.910 em Toritama. Isto representa $56,07 \%$ do total de vínculos no setor de confecção em Pernambuco. Além disto, $60,76 \%$ do total de estabelecimentos do Estado de Pernambuco no setor de confecção de artigos do vestuário e acessórios estão localizados nestes três municípios, sendo $27,3 \% \mathrm{em}$ Caruaru, 20,5\% em Santa Cruz do Capibaribe e 13,42\% em Toritama, no ano de 2015.

Caruaru se destaca na $5^{a}$ posiçáo entre os municípios com maior Produto Interno Bruto - PIB - do Estado de Pernambuco desde 2011, quando subiu da $7^{a}$ posiçấo que ocupava em 2010. Por sua vez, Santa Cruz do Capibaribe está na $17^{a}$ posição e Toritama na 35a , do total de 185 municípios do Estado de Pernambuco de acordo com o ranking do Instituto Brasileiro de Geografia e Estatística (IBGE, 2018).

Apesar do progresso econômico da Regiáo principalmente devido ao setor de confecção, deve ser levado em consideraçáo o impacto ambiental causado pelos efluentes despejados por estas indústrias, haja vista que é caracterizada como uma atividade econômica poluente. O processo de produção destas indústrias que passa pelas etapas de limpeza, tingimento e acabamento consomem grandes quantidades de água e, consequentemente, causam danos significativos aos rios com o despejo de efluentes industriais. Ferreira (2011) apud Toniollo, Zancan e Wüst (2015) aponta que os danos causados ao meio ambiente decorrem da utilização de insumos químicos e corantes nas atividades de tingimento e acabamento, 
uma vez que a água é utilizada nos processos de lavagem, coloração, transferência de calor, aquecimento ou resfriamento.

A poluição das águas dos rios configura um dos principais problemas ambientais, sociais e econômicos da atualidade. A degradação dos recursos hídricos é um reflexo do processo de urbanização sem planejamento, que faz com que o crescimento das cidades leve a um sistema de esgotamento sanitário inadequado.

O principal receptor de efluentes do Município de Caruaru é o Rio Ipojuca. Os Indicadores de Desenvolvimento Sustentável do IBGE (2010) apontaram que o Rio Ipojuca ocupava o terceiro lugar entre os rios mais poluídos do Brasil e apresentava-se poluído em todo o seu curso. Para Aprile e Parente (2003) isto se deve, dentre outros fatores, às indústrias implantadas no entorno da Bacia Hidrográfica do Rio Ipojuca cujos despejos líquidos apresentam características de toxicidade, com destaque para a indústria têxtil, destilarias, galvanoplastias e indústrias químicas direcionadas à produção de tintas e corantes. A consequência disto é a contaminação de solos e mananciais hídricos. Até os dias de hoje é perceptível a poluição causada pela tintura da lavagem de Jeans na Região, haja vista que muitas vezes o Rio apresenta diferentes coloraçóes.

Através de dados coletados no Sistema Nacional de Informações sobre Saneamento - SNIS - no ano de 2015 observa-se que apenas 28,6\%, aproximadamente, da água consumida pelos municípios com sede na Bacia do Rio Ipojuca é coletada pelo sistema de esgotamento sanitário e destes apenas $22,4 \%$ passa por algum processo de tratamento. Isto sugere que $77,5 \%$ da água consumida é despejada no rio sem o tratamento adequado.

O trabalho de Silva et al (2012) demonstrou esta falta de adequação com o uso da água nas lavanderias de Jeans em Caruaru. E uma breve caminhada pelo Agreste Pernambucano nos dias de hoje demonstrará que esta realidade ainda vigora até os dias atuais.

Por sua vez, os municípios de Santa Cruz do Capibaribe e Toritama despejam seus efluentes no Rio Capibaribe. De acordo com a Secretaria de Recursos Hídricos - SRH do Estado de Pernambuco (2010b) o Rio Capibaribe também se encontra poluído por resíduos sólidos e líquidos, orgânicos e inorgânicos, industriais e agrícolas, apresenta altas taxas de assoreamento e tem uma população estimada em 430 mil habitantes em seu entorno.

Os dados coletados no SNIS referente ao ano de 2015 mostram que 50,68\% da água consumida pelos municípios com sede na Bacia Hidrográfica do Rio Capibaribe são despejadas sem tratamento. Do volume total de água despejada sem tratamento o Município de Santa Cruz do Capibaribe é responsável por 3,11\% desse total, enquanto Toritama é responsável por $1,51 \%$. A maior parte do esgoto é despejado sem tratamento pelo município de Recife, com 49,41\% do total.

A crescente demanda pelos recursos hídricos está associada ao processo de urbanização, com a formaçáo de grandes centros urbanos e industriais. Esta necessidade se deve à dependência que há em relação a disponibilidade de água para abastecimento doméstico, processos industriais, atividades agrícolas, etc. Apesar de ser uma fonte renovável, a água doce é um recurso finito e vulnerável e deve ser entendido como "um recurso natural e bem econômico e social cujas quantidade e qualidade determinam a natureza de sua utilização." (BRASIL/MMA, 2012). 
Segundo Lunardi e Rabaiolli (2013), o crescimento acelerado da população é responsável pelo aumento na demanda pelos recursos hídricos, e o processo de degradação destes recursos ocorre com o desperdício e o uso inadequado da água, que causa escassez el ou poluição das águas. Sendo assim, Sperling (2005) afirma que o controle da qualidade da água deve ser feito a partir de um planejamento global, no decorrer de toda a bacia hidrográfica.

De acordo com a Agência Nacional de Águas - ANA (BRASIL/MMA/ANA, 2017a), os principais usos da água no Brasil são para irrigação, abastecimento humano e animal, industrial, geração de energia, mineração, aquicultura, navegação, turismo e lazer. Um estudo mais detalhado da ANA verificou que cerca de $67,2 \%$ da água consumida no Brasil é para irrigação, enquanto $9,5 \%$ é utilizada na indústria e $8,8 \%$ no abastecimento urbano. (BRASIL/MMA/ANA, 2017b).

No entanto, Moraes e Jordão (2002) apontaram que a maior parte da água que era retirada náo era consumida pelos indivíduos, ou seja, era utilizada no processo industrial e de irrigação, dentre outros. Além disso, a água retornava a sua fonte sem nenhuma alteração qualitativa de melhoria.

O despejo inadequado de esgoto doméstico e industrial nos rios impacta tanto na qualidade da água quanto na sua disponibilidade. Dessa forma, a poluição encarece o custo do tratamento da água para abastecimento público. De acordo com os índices de cobertura de esgotos no Brasil apresentados no atlas da Agência Nacional de Águas - ANA (BRASIL/ MMA/ANA, 2017b), os dados mostram que 38,6\% dos esgotos não são coletados e nem tratados, e 18,8\% são coletados, mas não são tratados.

Sendo assim, o problema que se levanta está relacionado aos custos ambientais, sociais e econômicos causados pela poluição dos Rios Ipojuca e Capibaribe, uma vez que a poluição destes rios além de aumentar os custos de tratamento da água causa externalidades negativas para os municípios com sede nestas bacias hídricas. Além de benefícios econômicos e sociais, a necessidade de valorar os custos de despoluição dos Rios Ipojuca e Capibaribe também é de extrema importância para benefício dos indivíduos, pois de acordo com Motta (1997) o bem-estar das pessoas é medido, além do consumo de bens e serviços, pelo consumo de amenidades de origem política, cultural, ambiental e de lazer.

A partir do que foi apresentado percebe-se a necessidade de avaliar possíveis soluçóes que busquem sanar gradativamente o problema da poluiçâo dos Rios Ipojuca e Capibaribe, através de projetos de despoluição que viabilizem a utilização adequada das águas destes rios pela população dos municípios que possuem sede urbana nas respectivas bacias hidrográficas. Para isso, sugere-se que os projetos sejam implementados partindo de uma cooperação entre os municípios.

Nesse sentido, o objetivo deste trabalho consiste em indicar a alocação dos custos de projetos de despoluiçáo para o Rio Ipojuca e o Rio Capibaribe entre os municípios com sede urbana nas bacias hidrográficas dos respectivos rios, a partir da análise do índice de esgoto que é despejado sem tratamento. Vários podem ser os projetos que atendam esta finalidade, ficando a critério do órgão gestor responsável pelos recursos hídricos da região. 
Pretende-se, ainda, apontar a importância da gestão dos recursos hídricos para os municípios que compóem o Polo de Confecçóes do Agreste, visto que as atividades econômicas realizadas nesta região demandam grande quantidade de água. Por fim, buscase apresentar dados que possam identificar se há alguma relação entre as características econômicas e demográficas dos municípios e o nível de poluição gerada por estes. Este trabalho segue a abordagem metodológica de Leite (2016), que fez o mesmo estudo para alocação dos custos de projetos de despoluição entre os municípios da Baía de Guanabara.

Além desta Introdução, este estudo compóe-se de um capítulo de Referencial Teórico, que foi composto por três seções: a seção 2.1 aborda sobre os princípios teóricos da Economia do Meio Ambiente, a seção 2.2 trata sobre a Teoria dos Jogos e na seção 2.3 é feita uma Revisão de Literatura sobre o tema; o capítulo três explicita os Procedimentos Metodológicos, apresentando as variáveis e fontes de dados e o método de análise; o capítulo quatro trata dos Resultados e Discussões, a partir da análise dos dados coletados; por fim, o capítulo cinco faz as Consideraçôes Finais sobre o estudo proposto.

\title{
2 Referencial Teórico
}

Neste capítulo, apresenta-se a literatura econômica que fundamenta o estudo.

\subsection{A Economia do Meio Ambiente e o Princípio do Poluidor Pagador}

Diante das mudanças ocorridas nos últimos anos percebe-se que a produção está em um ritmo mais acelerado. Porém, se faz necessário avaliar o impacto ambiental causado pelas atividades econômicas a fim de impor uma conscientização destinada a proteger os recursos naturais, o que pode ser um desafio econômico devido a necessidade de avanços tecnológicos que viabilizem o progresso econômico e, ao mesmo tempo, possibilitem a proteção e conservação ambiental.

Sendo assim, a Economia do Meio Ambiente surge como uma corrente que busca compreender a relação que há entre as atividades econômicas e o meio ambiente e, a partir daí, definir decisões ótimas que estabeleçam uma certa adequação entre a melhoria da qualidade ambiental e o comportamento do mercado. (THOMAS E CALLAN, 2010).

Na visão de Macedo (2002, p.206):

\begin{abstract}
A Economia Ambiental, ou Economia do Meio Ambiente, fundamenta-se na teoria neoclássica, segundo a qual os distúrbios ambientais são consequência das imperfeiçôes de mercado. Uma vez corrigidas essas imperfeições, via avanços tecnológicos e novos preços que incorporem os custos ambientais, o mercado promoverá, gradualmente, o equilíbrio das trocas entre economia e meio ambiente.
\end{abstract}

Porém, a relação entre a produção, o consumo e a sustentabilidade implica em um trade-off para a sociedade. "Muitos problemas ambientais têm fortes dimensóes intertemporais, isto é, importantes trade-offs entre o presente e o futuro." (FIELD, 2014, p.24).

O desenvolvimento sustentável deve compreender tanto a viabilidade econômica como ecológica, através de estratégias que possam redefinir as relaçóes ambientais na 
sociedade (BECKHAUSER; KROENKE; HEIN, 2017). Dessa forma, a economia ambiental desempenha um papel crucial para definir estratégias que permitam gerir e alocar os recursos naturais da melhor forma possível.

Faucheux e Noël (1998) fazem uma distinção entre economia dos recursos naturais e economia do meio ambiente. A primeira teoria analisa a relação que se dá com a transformação dos recursos naturais em bens econômicos, através da extraçáo destes recursos. A segunda teoria descreve o processo de gestão destes recursos naturais e analisa o impacto causado pelas atividades econômicas ao meio ambiente.

Thomas e Callan (2010) apresentam a relação entre as atividades econômicas e o meio ambiente através de um "Modelo do Balanço de Materiais", como apresentado na Figura 1. Dentro deste modelo está inserido o Fluxo Circular da Renda, que de acordo com Vasconcellos e Garcia (1998) estabelece as relaçóes entre os agentes econômicos a partir da formação e distribuição do produto e renda gerados pelas atividades econômicas. O modelo do balanço de materiais pretende mostrar as conexôes que devem ser observadas para que se obtenha uma relação adequada entre atividade econômica e o ambiente natural. Para tanto, é importante gerir os resíduos que retornam das atividades econômicas para o meio ambiente.

Figura 1 - Modelo do Balanço de Materiais

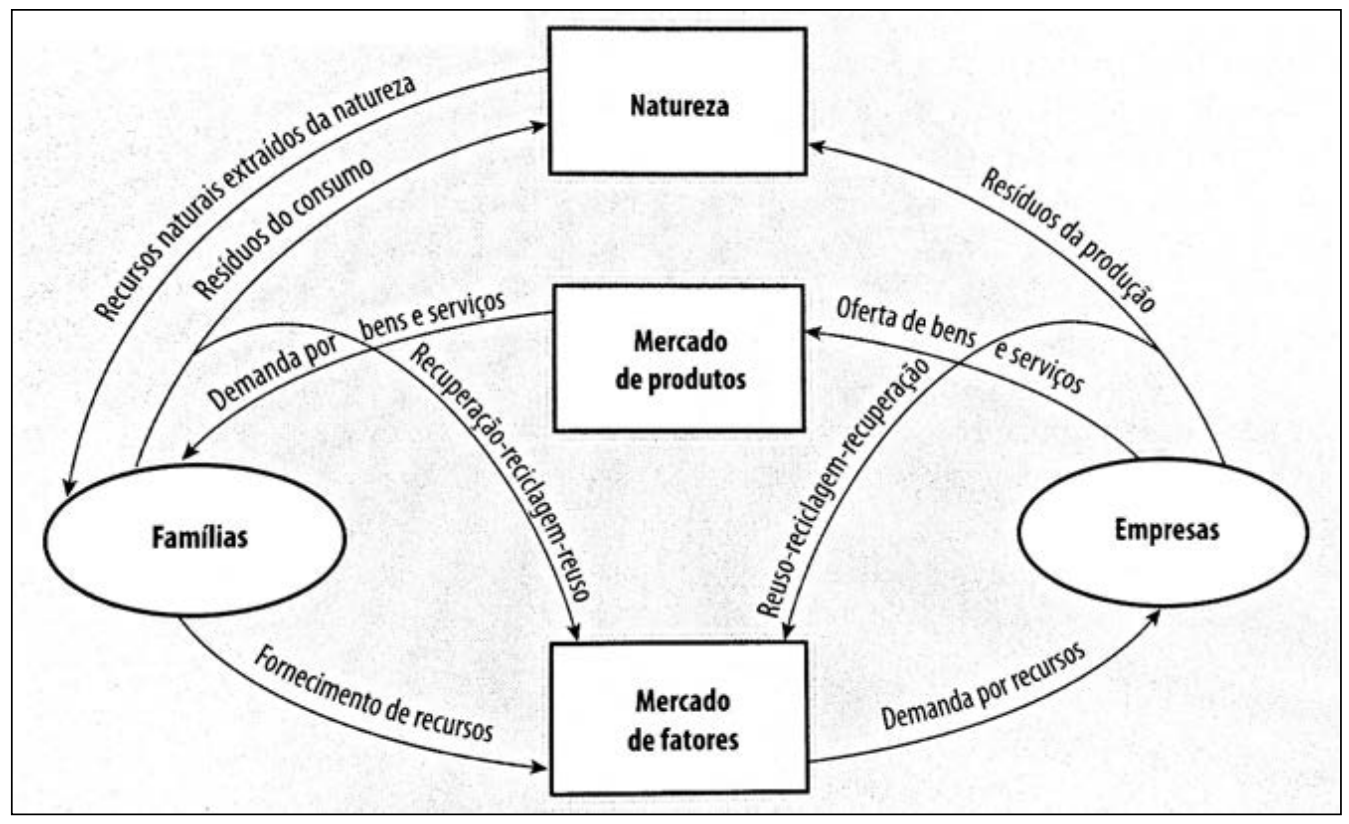

Fonte: Thomas e Callan (2010).

Nos últimos anos a importância da gestão ambiental vem ganhando destaque na busca de um controle e regulamentação mais eficazes sobre os recursos naturais. A importância de gerir os recursos hídricos é essencial para a tomada de decisão quanto à melhor forma de preservar a alocar este recurso, que é limitado e vulnerável, bem como de assegurar que 
tais decisões sejam viabilizadas e implementadas. Para tanto, se faz necessário condicionar à correta utilização dos recursos hídricos por parte dos usuários.

De acordo com os Indicadores de Desenvolvimento Sustentável do IBGE (2010) verifica-se que há uma necessidade de expansão no saneamento básico, principalmente através da coleta e tratamento de esgotos e a proteção de nascentes, mananciais, várzeas e áreas no entorno dos rios. Estas ações devem ser prioritárias devido à necessidade de conservação e preservação ${ }^{3}$ dos recursos hídricos, que se encontram comprometidos devido a poluição.

A Política Nacional de Recursos Hídricos através do art. $1^{\circ}$ (BRASIL/LEI N. 9.433, DE 8 DE JANEIRO DE 1997) estabelece que:

- A água é um bem de domínio público;

- A água é um recurso limitado, dotado de valor econômico;

- Em situações de escassez, o uso prioritário dos recursos hídricos é o consumo humano e a dessedentação (matar a sede) de animais;

- A gestão dos recursos hídricos deve sempre proporcionar o uso múltiplo das águas;

- A bacia hidrográfica é a unidade territorial para implementação da Política Nacional de Recursos Hídricos e atuação do Sistema Nacional de Gerenciamento de Recursos Hídricos;

- A gestão dos recursos hídricos deve ser descentralizada e contar com a participação do Poder Público, dos usuários e das comunidades.

Braga, Porto e Tucci (2006) indicam algumas informaçóes básicas que são necessárias para um gerenciamento eficaz dos recursos hídricos: características físicas dos sistemas hídricos, comportamento hidroclimátológico e dados socioeconômicos. A partir daí, podem-se tomar decisóes que garantam a sustentabilidade dos sistemas hídricos.

Uma gestão eficaz dos recursos hídricos é uma medida importante para reduzir os impactos causados nas bacias hidrográficas. A Figura 2 mostra a abrangência da Bacia Hidrográfica do Rio Ipojuca.

3 Por conservação entenda-se a produção com responsabilidade dos recursos naturais; por preservação entenda-se não tocar no meio ambiente. Assim, há espaços para preservar e outros para conservar no meio ambiente. 
Figura 2 - Bacia Hidrográfica do Rio Ipojuca

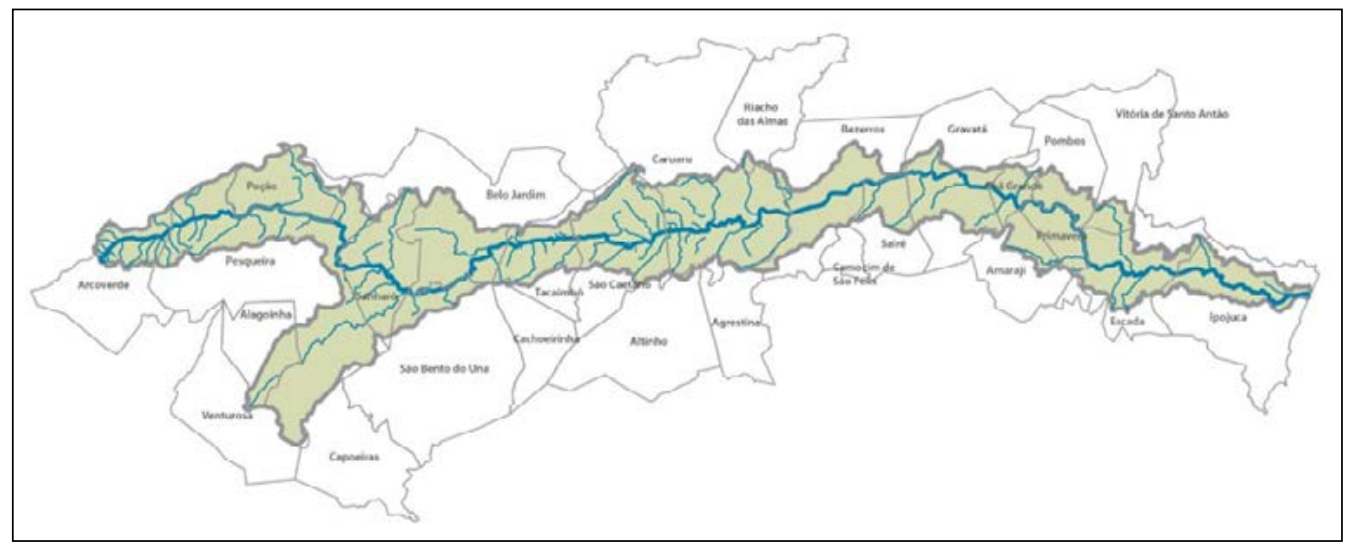

Fonte: PERNAMBUCO/SRHE (2018a)

A Bacia Hidrográfica do Rio Ipojuca está localizada no Estado de Pernambuco e faz ligação entre a Região Metropolitana do Recife (RMR) e sertão pernambucano. A sua localização estratégica contribui para o desenvolvimento socioeconômico do Estado, pois abrange espaços territoriais que atuam como polos de desenvolvimento regionais e locais (AGÊNCIA CONDEPE, 2005).

A Bacia abrange territórios parciais de 25 municípios e destes 12 possuem sede urbana dentro da Bacia Hidrográfica (BRASIL/IGAS, 2012). Os municípios com sede na regiâo da Bacia contribuíram com 12,36\% do PIB estadual no ano de 2015, destacando-se Ipojuca com 5,58\% e Caruaru com 3,9\%.

De acordo com a Agência Estadual de Meio Ambiente (PERNAMBUCO/CPRH, 2017) as águas do Rio Ipojuca sáo utilizadas para abastecimento público, recepção de efluentes domésticos e recepção de efluentes agroindustrial e industrial. As principais atividades industriais na Bacia são de produtos alimentares, minerais não-metálicos, sucroalcooleira, química, têxtil, metalúrgica, vestuário/artefatos/tecidos, couros, bebidas, produto farmacêutico/veterinário, perfumes/sabões/velas, material elétrico/comunicação, calçados, matéria plástica, agropecuária e borracha. Vale destacar a importância do Rio Ipojuca nas atividades econômicas dos municípios de Ipojuca, onde se localiza o Complexo Industrial e Portuário de Suape, e do Município de Caruaru, com os Distritos Industriais I e II. As atividades de confecção no agreste do Estado demandam grande quantidade de água e, dessa forma, causam danos ambientais significativos.

A Figura 3 mostra a abrangência da Bacia Hidrográfica do Rio Capibaribe. 


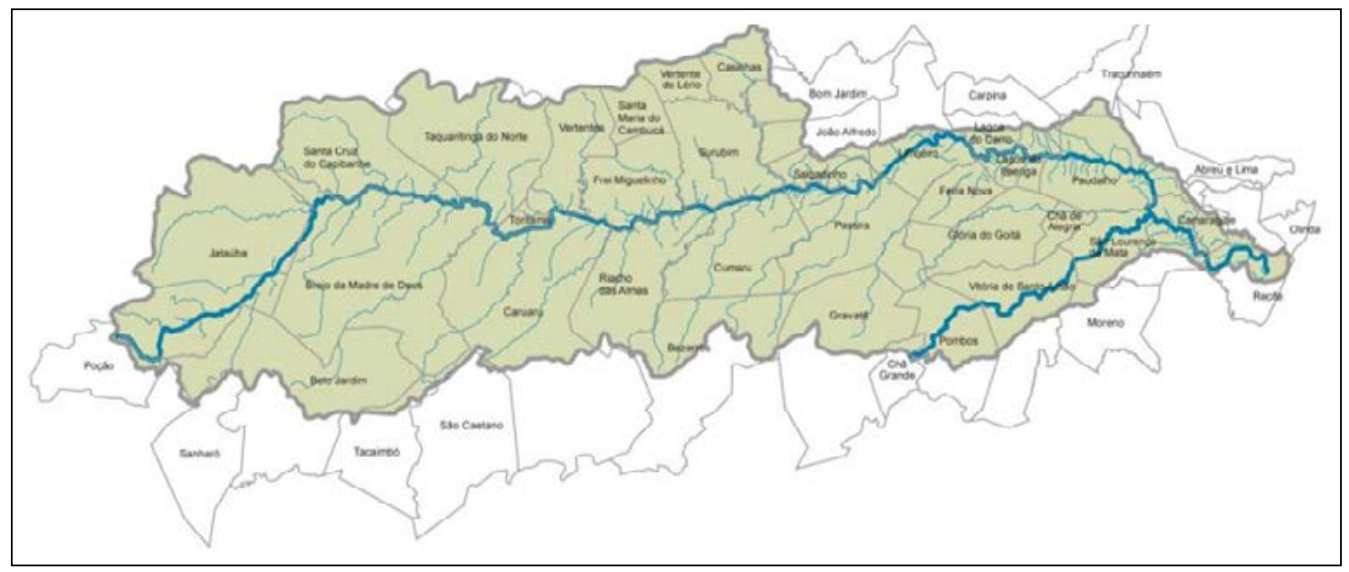

Fonte: PERNAMBUCO/SRHE (2018b).

A abrangência da Bacia Hidrográfica do Rio Capibaribe dificulta a sua gestão e a torna um ambiente difícil de ser gerido. Além da complexidade natural que apresenta no que diz respeito ao clima, relevo, solos etc., também se observa uma complexidade socioeconômica que exige um modelo de gestão hídrico e ambiental que atenda às suas especificidades regionais e locais (PERNAMBUCO/SRHE, 2018).

A Bacia Hidrográfica do Rio Capibaribe abrange 42 municípios e 26 possuem sede urbana dentro da Bacia. Os municípios com sede na região da Bacia Hidrográfica contribuem com grande parte do PIB do Estado de Pernambuco, visto que é onde está localizada a maior parte territorial da Região Metropolitana do Recife - RMR. No ano de 2015 os municípios com sede urbana nesta Bacia contribuíram com 39\% do PIB do Estado de Pernambuco, aproximadamente. Destaca-se, principalmente, o Município de Recife, com participação de 30,6\% do total do PIB do Estado, seguido de Vitória de Santo Antão e Camaragibe com participação de $1,96 \%$ e $0,88 \%$, respectivamente.

O Plano Hidroambiental da Bacia Hidrográfica do Rio Capibaribe, publicado através da SRH/PE (2010a), mostra que as atividades industriais mais comuns na Bacia Hidrográfica do Rio Capibaribe são associadas a produtos alimentares, minerais não-metálicos, têxtil, metalúrgicas, químicas, farmacêuticas e veterinárias, indústria sucroalcooleira, couros, matéria plástica, perfumes, sabōes, velas, bebidas, mecânica, material elétrico e de comunicação, material de transporte e madeira.

O custo para gerir os recursos hídricos, bem como para a implementação de projetos de despoluição, pode ser uma barreira para os órgãos responsáveis por este setor. Leite (2016) afirma que é necessário que para que esse quadro de degradação seja revertido são necessários investimentos em níveis vultosos, levantando discussões sobre quem deve arcar com tais custos e como estes deverão ser compartilhados.

Segundo Motta (1997), os custos da degradação ecológica geram externalidades negativas quando não são pagos por aqueles que a geram, comprometendo o sistema 
econômico. Tais custos irão afetar a terceiros se não houver a devida compensação. Por conta disso, é necessário que haja uma alocação eficiente desses custos.

Ainda de acordo com Motta (1997, p.1):

Qualquer que seja a forma de gestáo a ser desenvolvida por governos, organizaçōes não governamentais, empresas ou mesmo famílias, o gestor terá que equacionar o problema de alocar um orçamento financeiro limitado frente a inúmeras opçóes de gastos que visam diferentes opçóes de investimentos ou de consumo.

Pigou (1919) apud Varian (2012) cunhou o termo "internalização das externalidades negativas" como um modelo que solucionaria a questấo das falhas de mercado referentes aos custos ambientais. Isto deve ser feito através da cobrança de impostos/tributos aos agentes poluidores, pelo Estado, a fim de amenizar essas externalidades. Tal cobrança seria estipulada a partir da diferença entre o custo marginal privado e o custo marginal social. Ressalte-se que há uma literatura crítica a Pigou, Santos (2016), por exemplo, observa que náo haveria, verdadeiramente, uma preocupaçáo ambiental por parte de Pigou, mas sim uma tentativa por parte do teórico de corrigir falhas de mercado ao identificá-las a partir destas externalidades. De todo modo, não há como negar que foi um marco na literatura sobre a questáo ambiental na teoria econômica.

Este processo de internalização das externalidades negativas proposto por Pigou também é denominado por alguns autores como Princípio do Poluidor Pagador. Para Cánepa e Pereira (2002), a imposiçáo deste ônus deve ser tratada como um tributo corretivo visando melhorar e até mesmo recuperar os recursos naturais comprometidos pela poluição, visto que iria induzir os agentes poluidores a reduzir a emissão de poluentes a fim de evitar o pagamento de tais tributos.

Varian (2012) aponta que o problema com o imposto de Pigou é a falta de um mercado para gerir estas falhas, que seria solucionado se houvesse o mercado de poluição. Caso fosse possível este tipo de mercado o mesmo ajustaria as condiçóes necessárias para que se alcançasse um nível ótimo de poluição. Esta situação hipotética se concretizaria, por exemplo, se o poluidor pudesse "comprar" uma licença para poluir.

Uma abordagem alternativa para redução dos danos ambientais é apresentada por Thomas e Callan (2010), onde os autores afirmam que o pagamento de incentivos aos poluidores para que estes não poluam seria uma forma mais eficaz de alcançar tais objetivos. Isto seria feito através de subsídios ambientais, que pode se dar de duas formas: subsídio para equipamento de redução da poluição e subsídios para corte na poluição. Esta teoria equivale à internalização das externalidades negativas, de Pigou, e este tipo de subsídio também é conhecido como subsídio pigouviano. Porém, o subsídio é um imposto negativo que atua como um mecanismo de incentivo, gerando externalidades positivas.

Diante disso, deve-se buscar um nível ótimo de poluição, que exige a minimização dos custos sociais da poluiçáo. Isto ocorre quando se atinge o equilíbrio eficiente no sentido de Pareto de poluição, ou seja, quando o custo marginal de gerar poluição se iguala a zero (VARIAN, 2012). A Figura 4 representa a produção eficiente de Pareto para a poluição, com o equilíbrio entre os custos sociais e privados. 
Figura 4 - Produção eficiente de Pareto

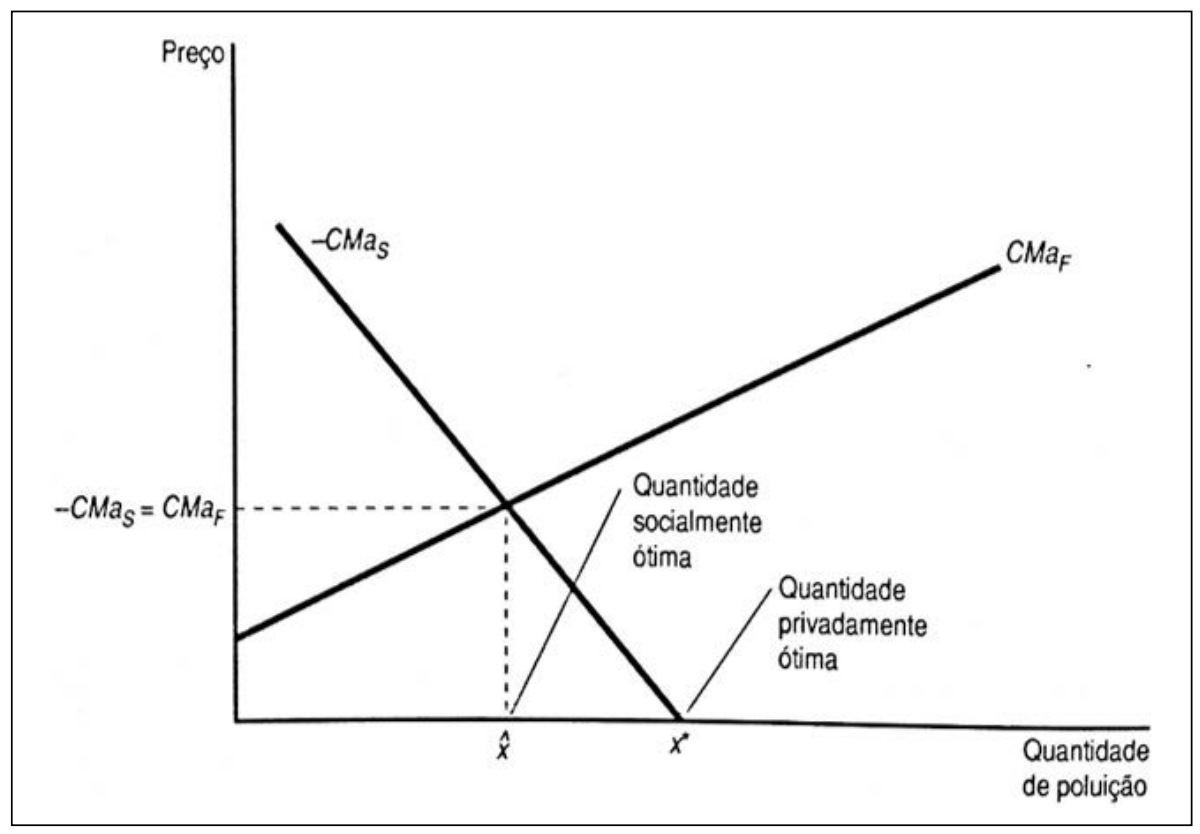

Fonte: Varian (2012).

\subsection{Teoria dos Jogos}

Em geral, a teoria dos jogos pode ser definida como um modelo que apresenta decisôes ótimas sob condições de conflito a partir da interação entre indivíduos. Osborne e Rubisntein (1994) descrevem um jogo como sendo um processo de interação estratégica entre agentes racionais.

Fiani (2006) cita os seguintes elementos essenciais de um jogo:

- Jogo: situação na qual os jogadores tomam decisões estratégicas que levam em conta as atitudes e respostas uns dos outros.

- Modelo formal: um jogo envolve técnicas descritivas e de análise, através de regras preestabelecidas.

- Payoffs: valores associados a um resultado possível. Estes resultados podem acarretar recompensas ou benefícios.

- Interações: as ações que cada agente, consideradas de forma individual, afetam ou não as jogadas dos demais jogadores.

- Agentes: é o indivíduo, ou grupo de indivíduos, com capacidade de decisão para efetuar os demais. Na teoria dos jogos o agente é denominado por jogador.

- Racionalidade: presume-se que os agentes são racionais e, por isso, os indivíduos utilizam os meios mais adequados para alcançarem os seus objetivos, independentemente de quais sejam estes. 
- Comportamento Estratégico: cada jogador toma uma decisão levando em consideração que os jogadores interagem entre si. Dessa forma, sua decisão terá consequências sobre os demais jogadores, assim como as decisóes de outros jogadores terão consequências sobre ele.

\subsubsection{Jogos Náo-Cooperativos $\mathrm{x}$ Jogos Cooperativos}

Nos jogos não-cooperativos os jogadores buscam unicamente maximizar seus ganhos. Não há qualquer tipo de colaboração entre os jogadores. De acordo com Ribeiro (2013, p.8) "como cada agente busca o benefício próprio, em algum momento haverá conflitos de interesses entre os jogadores."

A teoria de jogos cooperativos pode ser aplicada para resolver problemas de alocação de custos entre usuários de um mesmo serviço, bem como para problemas de alocação de benefícios. Pindyck (2013) afirma que em um jogo cooperativo os jogadores podem planejar estratégias em conjunto porque negociam contratos vinculativos (coalizóes) de cumprimento obrigatório.

Neste tipo de jogo, acordos de coalizóes permitem que os jogadores alcancem, através da cooperaçáo, payoffs maiores do que a soma que poderia ser alcançada por indivíduos se estes agissem por conta própria (NOVAES; ROSENBLATT, 1991). Porém, mesmo sendo um tipo de jogo mais vantajoso, há o risco de trapaça nos jogos cooperativos, caso em que um jogador não cumpre sua parte do acordo e mesmo assim se beneficia dos ganhos advindos do jogo (PINDYCK, 2013).

\subsubsection{Valor de Shapley}

$\mathrm{Na}$ análise da teoria dos jogos cooperativos existe um conceito conhecido como o valor de Shapley, que é um método de solução para este tipo de jogo. Shapley (1953) apud Salgueiro (2009) definiu um único valor para jogos cooperativos que abrange todo o conjunto de soluções através de uma função característica, que seria a função custo. Esta funçáo deve alocar a cada jogador uma média ponderada de todos os custos marginais referentes à sua participação em coalizóes. Segundo este critério, quem incrementa mais no custo total deve arcar com custos maiores.

De acordo com Ayala (2008) o Valor de Shapley pode ser visto como uma solução igualitária da repartição de benefícios definido através do valor médio dos benefícios incrementais de inclusão de um agente. Leite (2009) classifica o valor de Shapley como sendo uma forma justa de partição dos excedentes, em que a quantia/benefício que o indivíduo recebe é determinada por sua contribuição.

Em um jogo cooperativo denotado por $(N, \mathcal{v}), N$ representa a grande coalizão formada por um conjunto $N=\{1, \ldots, n\}$ de jogadores, e $v$ é a função característica que descreve o valor de cada coalizão. Segundo Montet e Serra (2003) apud LEITE (2016, p.3), "o valor da coalizão é exatamente a quantia que os integrantes de $S$ dividirão entre si e é visto como o máximo payoff que eles poderiam garantir independente das ações tomadas pelos jogadores em $N \backslash S . "$ 
Para o cálculo do valor de Shapley devem ser considerados, de acordo com Serrano (2007), os seguintes axiomas:

(i) Eficiência: Os payoffs devem somar $v(N)$, o que significa que se produz uma distribuição exaustiva do valor total da grande coalizão.

(ii) Simetria: Se dois jogos são idênticos, exceto quanto à ordem na qual os seus jogadores estão listados, o valor de Shapley para os jogadores são os mesmos.

(iii) Aditividade: a solução para a soma de dois jogos deve ser a soma que é atribuída a cada um dos dois jogos.

(iv) Jogador dummy: se um jogador não contribui em nada na coalizão, este não deve receber nenhum valor resultante da solução desta coalizão.

Sendo assim, existe uma função característica que atende a todos os axiomas que, de forma simples, basta ordenar os jogadores a partir dos custos gerados por estes, medir a contribuição marginal de cada um e obter a média em relação ao grupo de jogadores.

\subsection{Revisão de Literatura}

Estudos sobre problemas ambientais estão em evidência em uma tentativa de resignificar as relaçóes entre o meio ambiente e a sociedade moderna. Diante disto, buscase destacar os impactos ambientais causados pelas atividades econômicas a fim de entender em que ponto poderia se reverter, ou pelo menos amenizar, este cenário de degradação ambiental.

Santos (2016) aponta que a degradação ambiental está se agravando devido ao grande crescimento econômico mundial dos últimos cinquenta anos. Por conta disso, o autor afirma que é necessário formular políticas públicas que visem reduzir o impacto ambiental, incluindo variáveis não-econômicas no planejamento destas políticas. Neste cenário, destaca-se a Economia Ambiental que busca, principalmente, compreender o papel do meio ambiente para a teoria econômica.

Martine e Alves (2015) afirmam que o desenvolvimento econômico se acentuou com a aceleração das atividades no pós-guerra, através do desenvolvimento tecnológico que desencadeou uma expansão na produção. Porém, era previsível que esse crescimento acarretaria em crises ambientais, uma vez que foi baseado na exploração de recursos não renováveis, causando danos muitas vezes irreparáveis, tais como emissão de poluentes na atmosfera, redução da biodiversidade, poluição das águas, etc. De forma que o peso das questôes ambientais nas discussões econômicas vem se tornando mais evidente nos últimos anos.

A importância de formular políticas públicas para gerir os recursos ambientais é avaliada por Brito (2016) como uma solução para a reduzir a degradação qualitativa do meio ambiente. Ela aponta para uma Política de Pagamento por Serviços Ambientais para contribuir com a conservação de áreas naturais, que seria realizada através de uma ação estatal que visasse incentivar a restauração e conservação destas áreas.

Para que tal política possa ser implementada seria necessário viabilizar um sistema de pagamentos com o maior ganho ambiental e social possível. Além disso, ressalta a discussão 
sobre a importância de valorar os recursos ambientais como uma solução para a gestáo dos recursos naturais. Isto seria feito através de uma análise social de custo-benefício. A justificativa para valoração ambiental é que quando os custos dos danos ambientais não são pagos por quem causa os danos, estes custos geram externalidades para o sistema econômico.

O princípio poluidor pagador foi avaliado para a gestão dos recursos hídricos em um estudo de Gutierrez, Fernandes e Rauen (2017), em que os autores discutem o caráter de cobrança pelo uso dos recursos hídricos. Os autores afirmam que é necessário desenvolver estratégias que direcionem à correta utilização dos recursos hídricos, visando a sustentabilidade destes recursos a longo prazo. Os incentivos econômicos podem ser um instrumento eficaz para gestâo dos recursos hídricos, recompensando os usuários que, por exemplo, reduzam o desperdício de água.

Ainda tratando sobre os recursos hídricos, Silva (2012), um pouco antes dos autores supracitados, levantou a discussão da escassez de água, que considera um problema muito mais relacionado ao uso irracional deste recurso do que a fatores climáticos e geográficos. $\mathrm{O}$ autor afirma que para preservar os corpos hídricos deveria haver uma gestáo eficiente, buscando o equilíbrio inter-regional e intertemporal da água. O processo para que haja a racionalização dos recursos hídricos passaria pelas etapas de redução no consumo, reutilização e reciclagem das águas.

\section{Procedimentos Metodológicos}

Após a delimitação do problema, buscou-se analisar as principais orientaçóes e abordagens sobre o mesmo, procurando identificar as estratégias utilizadas na investigação científica da temática em questão. Posteriormente, foram analisadas discussóes sobre o assunto, bem como algumas das principais preocupaçôes observadas no meio acadêmico.

Esta pesquisa tem um caráter exploratório que segundo Gil (2002) tem como objetivo explicitar o problema e construir hipóteses acerca do mesmo. Também de acordo com os princípios de Koche (2011, p. 123) "a pesquisa bibliográfica se desenvolve tentando explicar um problema utilizando o conhecimento disponível a partir das teorias publicadas em livros ou obra congêneres [...] um instrumento indispensável para qualquer tipo de pesquisa”.

Posteriormente, recorreu-se a uma pesquisa de natureza descritiva, delineando as características de determinado fenômeno e estabelecendo as relaçôes entre variáveis (GIL, 2002). Nesta fase, buscou-se selecionar uma base de dados adequada que permitisse atender o objetivo proposto. Por fim, confrontou-se a discussão teórica com os dados disponíveis. Neste sentido, justifica-se o corte temporal para 2015, haja vista que é o último ano com todas as variáveis disponíveis.

\subsection{Variáveis e Fontes de Dados}

Os dados apresentados foram coletados no Sistema Nacional de Informaçóes sobre Saneamento (SNIS), base de dados do Ministério das Cidades do IBGE. Devido a abrangência e complexidade das Bacias Hidrográficas dos Rios Ipojuca e Capibaribe é necessário que possa ser viabilizada uma gestáo cooperativa entre os municípios que possuem 
sede urbana nas respectivas bacias hidrográficas. Dessa forma, a análise foi realizada visando alocar os custos entre todos os municípios que estão localizados nestas bacias hídricas.

A variável determinante para alocar os custos de projetos de despoluição foi o volume de esgoto náo tratado referido à água consumida $\left(\mathrm{em} 1000 \mathrm{~m}^{3}\right.$ ) que cada município despejou nas respectivas bacias hidrográficas ao longo do ano de 2015. Esta variável foi estabelecida a partir da diferença entre o volume de água consumido por cada município e o volume de esgoto tratado. Dessa forma, os dados analisados mostram o volume de água consumido pelos municípios e que não recebe nenhum tipo de tratamento, sejam estes caracterizados como esgotos domésticos ou industriais.

O Quadro 1 apresenta os dados utilizados para estabelecer a variável determinante em relação à Bacia Hidrográfica do Rio Ipojuca.

Quadro 1 - Dados do volume de água e esgoto dos municípios com sede urbana na Bacia Hidrográfica do Rio Ipojuca

\begin{tabular}{|c|c|c|c|c|}
\hline $\begin{array}{c}\text { Municípios } \\
\text { com sede na } \\
\text { Bacia do Rio } \\
\text { Ipojuca }\end{array}$ & $\begin{array}{c}\text { Volume } \\
\text { de água } \\
\text { consumido } \\
\left(1000 \mathrm{~m}^{3} / \mathrm{ano}\right) \\
\end{array}$ & $\begin{array}{c}\text { Volume } \\
\text { de esgotos } \\
\text { coletados } \\
\left(1000 \mathrm{~m}^{3} / \mathrm{ano}\right) \\
\end{array}$ & $\begin{array}{c}\text { Volume de } \\
\text { esgotos tratado } \\
\left(1000 \mathrm{~m}^{3} / \mathrm{ano}\right)\end{array}$ & $\begin{array}{c}\text { Volume de esgoto náo } \\
\text { tratado referido à água } \\
\text { consumida ( } 1000 \mathrm{~m}^{3} / \text { ano) }\end{array}$ \\
\hline Belo Jardim & $1.743,39$ & $1.448,34$ & 0 & $1.743,39$ \\
\hline Bezerros & $1.479,63$ & - & - & $1.479,63$ \\
\hline Caruaru & $11.340,92$ & $5.027,29$ & $5.027,29$ & $6.313,63$ \\
\hline Chã Grande & 371,36 & - & - & 371,36 \\
\hline Escada & $1.483,12$ & - & - & $1.483,12$ \\
\hline Gravatá & $4.056,05$ & 55,9 & 55,9 & $4.000,15$ \\
\hline Ipojuca & $1.597,89$ & 235,11 & 235,11 & $1.362,78$ \\
\hline Poção & 9,75 & - & - & 9,75 \\
\hline Primavera & 197,85 & - & - & 197,85 \\
\hline Sanharó & 412,66 & - & - & 412,66 \\
\hline São Caetano & 744,15 & - & - & 744,15 \\
\hline Tacaimbó & 242,39 & - & - & 242,39 \\
\hline
\end{tabular}

Fonte: Elaboração das autoras, dados do SNIS (2018).

A partir desses dados percebe-se que apenas quatro municípios possuem sistema de coleta de esgoto, e destes apenas três realizam algum tipo de tratamento nas águas coletadas. O Município de Belo Jardim coleta um grande volume de esgoto, cerca de $83 \%$ da água consumida. Porém, não realiza tratamento deste esgoto antes de despejá-lo no Rio Ipojuca. Caruaru coleta aproximadamente $44 \%$ do esgoto referente à água consumida e realiza tratamento em todo o volume de esgoto que é coletado. Da mesma forma, os municípios de Ipojuca e Gravatá realizam o tratamento em todo o volume de esgoto coletado, que é de aproximadamente $14,7 \%$ e 1,4\% do volume de água consumido, respectivamente.

A mesma análise é feita para a Bacia do Rio Capibaribe, apresentada no Quadro 2: 
Quadro 2 - Dados do volume de água e esgoto dos municípios com sede urbana na Bacia Hidrográfica do Rio Capibaribe

\begin{tabular}{|c|c|c|c|c|}
\hline $\begin{array}{l}\text { Municípios com } \\
\text { sede na Bacia do } \\
\text { Rio Capibaribe }\end{array}$ & $\begin{array}{c}\text { Volume } \\
\text { de água } \\
\text { consumido } \\
\left(1000 \mathrm{~m}^{3} / \mathrm{ano}\right)\end{array}$ & \begin{tabular}{|c|} 
Volume \\
de esgotos \\
coletados \\
$\left(1000 \mathrm{~m}^{3} / \mathrm{ano}\right)$
\end{tabular} & $\begin{array}{c}\text { Volume } \\
\text { de esgotos } \\
\text { tratado } \\
\left(1000 \mathrm{~m}^{3} / \mathrm{ano}\right)\end{array}$ & $\begin{array}{c}\text { Volume de esgoto náo } \\
\text { tratado referido à água } \\
\text { consumida ( } 1000 \mathrm{~m}^{3} / \text { ano) }\end{array}$ \\
\hline $\begin{array}{l}\text { Brejo da Madre } \\
\text { de Deus }\end{array}$ & 567,91 & - & - & 567,91 \\
\hline Camaragibe & $3.719,55$ & 67,4 & 67,4 & $3.652,15$ \\
\hline Carpina & $2.292,66$ & - & - & $2.292,66$ \\
\hline Casinhas & 40,70 & - & - & 40,70 \\
\hline Chã de Alegria & 246,96 & - & - & 246,96 \\
\hline Cumaru & 217,80 & - & - & 217,80 \\
\hline Feira Nova & 529,31 & - & - & 529,31 \\
\hline Frei Miguelinho & 124,77 & - & - & 124,77 \\
\hline Glória do Goitá & 577,41 & - & - & 577,41 \\
\hline Jataúba & - & - & - & - \\
\hline Lagoa do Itaenga & 429,59 & - & - & 429,59 \\
\hline Limoeiro & $1.317,92$ & - & - & $1.317,92$ \\
\hline Passira & 386,48 & - & - & 386,48 \\
\hline Paudalho & 961,19 & - & - & 961,19 \\
\hline Pombos & 674,65 & - & - & 674,65 \\
\hline Recife & $60.075,97$ & $39.532,18$ & $39.400,00$ & $20.675,97$ \\
\hline Riacho das Almas & 466,41 & - & - & 466,41 \\
\hline $\begin{array}{l}\text { Santa Cruz do } \\
\text { Capibaribe }\end{array}$ & $1.299,61$ & - & - & $1.299,61$ \\
\hline $\begin{array}{l}\text { Santa Maria do } \\
\text { Cambucá }\end{array}$ & 123,18 & - & - & 123,18 \\
\hline $\begin{array}{l}\text { São Lourenço da } \\
\text { Mata }\end{array}$ & $2.340,60$ & 323,99 & 323,99 & $2.016,61$ \\
\hline Surubim & $1.534,77$ & - & - & $1.534,77$ \\
\hline $\begin{array}{l}\text { Taquaritinga do } \\
\text { Norte }\end{array}$ & 36,82 & - & - & 36,82 \\
\hline Toritama & 630,06 & - & - & 630,06 \\
\hline Vertente do Lério & 46,25 & - & - & 46,25 \\
\hline Vertentes & 306,95 & - & - & 306,95 \\
\hline $\begin{array}{l}\text { Vitória de Santo } \\
\text { Antáo }\end{array}$ & $3.609,71$ & 924,09 & 924,09 & $2.685,62$ \\
\hline
\end{tabular}

Fonte: Elaboração das autoras, dados do SNIS (2018). 
Dentre os municípios que possuem sede urbana na Bacia Hidrográfica do Rio Capibaribe apenas quatro deles têm sistema de coleta de esgotos, os mesmos que realizam algum tipo de tratamento antes de despejarem a água consumida no Rio Capibaribe. Recife coleta $65,8 \%$ de esgoto referente à água consumida e realiza tratamento em quase todo o esgoto coletado, aproximadamente 65,6\%. Vitória de Santo Antáo coleta 25,6\% de esgoto e faz tratamento em todo o volume desse esgoto coletado, assim como Sáo Lourenço da Mata e Camaragibe, com $13,84 \%$ e $1,81 \%$ de coleta e tratamento de esgoto em relação à água consumida, respectivamente.

\subsection{Método de Análise}

O método utilizado para calcular a alocaçáo dos custos de despoluição entre os municípios analisados foi o Valor de Shapley, seguindo a abordagem metodológica proposta por Leite (2016). Para o caso em análise esta teoria pode ser modelada a partir dos custos que cada agente deve arcar a partir da sua "contribuição" na poluição da bacia hidrográfica.

A equação característica para o valor de Shapley, representado por $\Phi(v)$, mostra o valor que cada jogador irá contribuir na grande coalizão e é calculado da seguinte forma:

$$
\Phi_{i}(v)=\Sigma S \subseteq N \frac{(s-1) !(n-s) !}{n !}[\mathrm{v}(S)-v(S-\{i\})], \forall i \in N
$$

onde:

$n$ - número de elementos do conjunto $N$;

$S$ - número de jogadores na coalizão $S$; e

$v(S)-v(S-\{i\})$ - contribuição marginal do jogador $i$ quando ele se associa a outros jogadores para formar a coalizão $S$.

Um caso específico da utilização desta teoria foi proposto por Littlechild e Owen (1973), denominado por Leite (2016) como “jogo do aeroporto". Neste caso, os jogadores possuem diferentes características e são divididos em grupos. A função custo de qualquer grupo formado no jogo será dada pelo custo do maior jogador pertencente a este grupo, ou seja, o que terá maior necessidade de custo. Além disso, os autores estabelecem o caso em que há apenas um jogador de cada tipo. No caso analisado ocorre o seguinte: os jogadores são os municípios com diferentes características, ou seja, cada município possui um "nível" diferente de poluição. Porém, só existe um tipo de cada jogador, dado que só existe um município para cada nível de poluição.

A fórmula para este caso específico do Valor de Shapley é a seguinte:

$$
\Phi_{i}=\Phi_{i-1}+\left(c_{i}-c_{i-1}\right) /(n-i+1)
$$

Em que $c i$ é a funçáo custo que representa o custo incremental necessário para que o projeto possa atender o jogador que demande maiores custos, e é dada por:

$$
\mathrm{c}_{i}=\sum_{l=1}^{i} b_{l} \mathrm{c}_{i}=\sum_{l=1}^{i} b_{l}, \text { com } b_{i} \geq 0 \text { e } i=1, \ldots, \mathrm{n}
$$

E $b_{i}$ é a média ponderada de todos os custos marginais referentes participação de cada município em coalizōes, dada da seguinte forma: 


$$
\mathrm{b}_{i}=\frac{\mathrm{x}_{i}}{\mathrm{x}_{1}+\ldots+\mathrm{x}_{\mathrm{m}}} \mathrm{c}(\mathrm{N}), \text { para } \mathrm{i} \in\{1, \ldots, \mathrm{m}\}
$$

Onde:

$X i$ - volume de esgoto não tratado referido à água consumida despejado por cada município na Bacias Hidrográfica dos rios Ipojuca e Capibaribe;

$c(N)$ - é o custo total a ser alocado

O Quadro 3 apresenta os dados utilizados para alocação dos custos de despoluição entre os 12 municípios que possuem sede urbana na Bacia Hidrográfica do Rio Ipojuca, que serão utilizados para o cálculo do Valor de Shapley.

Quadro 3 - Dados para alocação dos custos de despoluição entre os municípios com sede na Bacia Hidrográfica do Rio Ipojuca

\begin{tabular}{|c|l|r|r|}
\hline $\boldsymbol{i}$ & $\begin{array}{c}\text { Municípios com sede na Bacia do } \\
\text { Rio Ipojuca }\end{array}$ & \multicolumn{1}{c|}{$\boldsymbol{b}_{\boldsymbol{i}}$} & \multicolumn{1}{c|}{$\boldsymbol{c}_{\boldsymbol{i}}$} \\
\hline 1 & Poção & 0,0531 & 0,0531 \\
\hline 2 & Primavera & 1,0776 & 1,1307 \\
\hline 3 & Tacaimbó & 1,3201 & 2,4508 \\
\hline 4 & Chã Grande & 2,0226 & 4,4734 \\
\hline 5 & Sanharó & 2,2475 & 6,7209 \\
\hline 6 & Săo Caetano & 4,0529 & 10,7738 \\
\hline 7 & Ipojuca & 7,4222 & 18,1960 \\
\hline 8 & Bezerros & 8,0586 & 26,2546 \\
\hline 9 & Escada & 8,0776 & 34,3322 \\
\hline 10 & Belo Jardim & 9,4951 & 43,8274 \\
\hline 11 & Gravatá & 21,7863 & 65,6136 \\
\hline 12 & Caruaru & 34,3864 & 100 \\
\hline
\end{tabular}

Fonte: Elaboração das autoras (2018).

Por sua vez, o Quadro 4 apresenta os dados que foram utilizados para o cálculo do Valor de Shapley, a fim de alocar os custos de despoluiçấo entre os 26 municípios que possuem sede urbana na Bacia Hidrográfica do Rio Capibaribe. Mas o Município de Jataúba, apesar de possuir sede urbana na Bacia Hidrográfica do Rio Capibaribe, não apresenta dados de consumo de água e esgotamento sanitário, impossibilitando a análise de custos. Supôe-se, todavia, que o impacto referente à retirada deste Município para alocação dos custos seja pouco relevante para a análise, já que possui uma das menores populaçóes dentre os municípios analisados, ocupando a vigésima posição e, consequentemente, a poluição causada pelo despejo de esgoto sem tratamento também será pouco relevante. Dessa forma, os custos foram alocados entre 25 municípios. 
Quadro 4 - Dados para alocação dos custos de despoluição entre os municípios com sede na Bacia Hidrográfica do Rio Capibaribe

\begin{tabular}{|c|c|c|c|}
\hline$i$ & $\begin{array}{c}\text { Municípios com sede na Bacia do } \\
\text { Rio Capibaribe }\end{array}$ & $b_{i}$ & $c_{i}$ \\
\hline 1 & Taquaritinga do Norte & 0,0880 & 0,0880 \\
\hline 2 & Casinhas & 0,0973 & 0,1853 \\
\hline 3 & Vertente do Lério & 0,1105 & 0,2958 \\
\hline 4 & Santa Maria do Cambucá & 0,2944 & 0,5902 \\
\hline 5 & Frei Miguelinho & 0,2982 & 0,8884 \\
\hline 6 & Cumaru & 0,5205 & 1,4089 \\
\hline 7 & Chã de Alegria & 0,5902 & 1,9992 \\
\hline 8 & Vertentes & 0,7336 & 2,7327 \\
\hline 9 & Passira & 0,9237 & 3,6564 \\
\hline 10 & Lagoa do Itaenga & 1,0267 & 4,6831 \\
\hline 11 & Riacho das Almas & 1,1147 & 5,7978 \\
\hline 12 & Feira Nova & 1,2650 & 7,0628 \\
\hline 13 & Brejo da Madre de Deus & 1,3573 & 8,4201 \\
\hline 14 & Glória do Goitá & 1,3800 & 9,8001 \\
\hline 15 & Toritama & 1,5058 & 11,3059 \\
\hline 16 & Pombos & 1,6124 & 12,9183 \\
\hline 17 & Paudalho & 2,2972 & 15,2155 \\
\hline 18 & Santa Cruz do Capibaribe & 3,1060 & 18,3215 \\
\hline 19 & Limoeiro & 3,1498 & 21,4713 \\
\hline 20 & Surubim & 3,6680 & 25,1393 \\
\hline 21 & São Lourenço da Mata & 4,8196 & 29,9590 \\
\hline 22 & Carpina & 5,4794 & 35,4383 \\
\hline 23 & Vitória de Santo Antão & 6,4185 & 41,8568 \\
\hline 24 & Camaragibe & 8,7285 & 50,5853 \\
\hline 25 & Recife & 49,4147 & 100 \\
\hline
\end{tabular}

Fonte: Elaboração própria (2018).

Com estes dados foi calculado o Valor de Shapley para cada município, originando um valor, em percentual, que representa a participação de cada município em termos de contribuição em projetos de despoluição das respectivas bacias hidrográficas.

\section{Resultados e Discussão}

A Tabela 1 apresenta o Valor de Shapley, em percentual, para a alocação dos custos do projeto de despoluição entre os municípios que possuem sede urbana na Bacia do Rio Ipojuca. A partir destes dados pode-se inferir a porcentagem que cada município deveria 
contribuir nos custos do projeto de despoluição. Este valor foi calculado através da fórmula do Valor de Shapley para o caso especial em que há apenas 1 tipo de cada jogador, proposta por Littlechild e Owen (1973) apud Leite (2016), que no caso apresentado seriam os "municípios poluidores":

$$
\Phi_{i}=\Phi_{i-1}+\left(C_{i}-C_{i-1}\right) /(n-i+1)
$$

Tabela 1 - Valor de Shapley para os municípios com sede na Bacia do Rio Ipojuca

\begin{tabular}{|c|c|c|}
\hline$i$ & $\begin{array}{c}\text { Municípios com sede na Bacia do Rio } \\
\text { Ipojuca }\end{array}$ & Valor de Shapley (\%) \\
\hline 1 & Poção & 0,0044 \\
\hline 2 & Primavera & 0,1024 \\
\hline 3 & Tacaimbó & 0,2344 \\
\hline 4 & Chã Grande & 0,4591 \\
\hline 5 & Sanharó & 0,7401 \\
\hline 6 & São Caetano & 1,3191 \\
\hline 7 & Ipojuca & 2,5561 \\
\hline 8 & Bezerros & 4,1678 \\
\hline 9 & Escada & 6,1872 \\
\hline 10 & Belo Jardim & 9,3523 \\
\hline 11 & Gravatá & 20,2454 \\
\hline 12 & Caruaru & 54,6318 \\
\hline
\end{tabular}

Fonte: Elaboração das autoras (2018).

Os dados revelam que a maior parte dos custos de despoluição seria alocada para o Município de Caruaru (54,63\%), visto que é o Município que mais despeja esgoto sem tratamento, contribuindo para a poluiçáo do Rio Ipojuca.

O Município de Ipojuca, apesar de concentrar a segunda maior população urbana dentre os municípios analisados e possuir o maior PIB destes, deveria arcar com apenas 2,55\% dos custos de despoluição, atrás de outros cinco municípios. Excetuando o Município de Ipojuca percebe-se que quanto maior a população dos municípios maiores os custos que os municípios teriam que arcar para despoluir o Rio Ipojuca.

A Tabela 2 apresenta os custos de despoluiçáo que cada município que possui sede na Bacia Hidrográfica do Rio Capibaribe teria que arcar, a partir da análise do Valor de Shapley. 
Tabela 2 - Valor de Shapley para os Municípios com sede na Bacia do Rio Capibaribe

\begin{tabular}{|c|c|c|}
\hline$i$ & $\begin{array}{c}\text { Municípios com sede na Bacia do Rio } \\
\text { Capibaribe }\end{array}$ & Valor de Shapley (\%) \\
\hline 1 & Taquaritinga do Norte & 0,0035 \\
\hline 2 & Casinhas & 0,0076 \\
\hline 3 & Vertente do Lério & 0,0124 \\
\hline 4 & Santa Maria do Cambucá & 0,0258 \\
\hline 5 & Frei Miguelinho & 0,0400 \\
\hline 6 & Cumaru & 0,0660 \\
\hline 7 & Chã de Alegria & 0,0971 \\
\hline 8 & Vertentes & 0,1378 \\
\hline 9 & Passira & 0,1921 \\
\hline 10 & Lagoa do Itaenga & 0,2563 \\
\hline 11 & Riacho das Almas & 0,3306 \\
\hline 12 & Feira Nova & 0,4210 \\
\hline 13 & Brejo da Madre de Deus & 0,5254 \\
\hline 14 & Glória do Goitá & 0,6404 \\
\hline 15 & Toritama & 0,7773 \\
\hline 16 & Pombos & 0,9385 \\
\hline 17 & Paudalho & 1,1938 \\
\hline 18 & Santa Cruz do Capibaribe & 1,5820 \\
\hline 19 & Limoeiro & 2,0320 \\
\hline 20 & Surubim & 2,6433 \\
\hline 21 & São Lourenço da Mata & 3,6072 \\
\hline 22 & Carpina & 4,9771 \\
\hline 23 & Vitória de Santo Antão & 7,1166 \\
\hline 24 & Camaragibe & 11,4808 \\
\hline 25 & Recife & 60,8955 \\
\hline
\end{tabular}

Fonte: Elaboração das autoras (2018).

O Município de Recife arcaria com mais da metade de todos os custos em projetos de despoluição. Dentre os municípios com sede urbana na Bacia Hidrográfica do Rio Capibaribe, os três municípios com maior população também são os municípios que teriam que arcar com os maiores custos de despoluição do Rio Capibaribe: Recife, Camaragibe e Vitória de Santo Antâo.

Santa Cruz do Capibaribe tem a quinta maior população e seria o oitavo Município a arcar com os maiores custos de despoluição. Toritama ocupa o décimo primeiro lugar entre os municípios com maior população dentre os analisados, coincidindo com a posição ocupada para os custos de despoluição. 
O estudo proposto por Leite (2016) mostrou que o método de alocação baseado no valor de Shapley seguiu a proporção populacional, já que os municípios com maior número de habitantes arcariam com maiores custos. Algumas exceçóes podem ser observadas em municípios que possuem algum planejamento que vise a redução dos danos ambientais. Ainda de acordo com o autor "é provável que a combinação de fatores como locais populosos, crescimento demográfico desordenado e presença maciça de habitaçóes irregulares e/ou em condições precárias, como as favelas, dificultem a prestação dos serviços de saneamento." (LEITE, 2016, p.11)

Dessa forma, percebe-se que o custo de despoluição está diretamente relacionado à dinâmica demográfica dos municípios, uma vez que quanto maior o número de habitantes maior será a incidência de despejo de efluentes nos corpos hídricos, tanto por esgotos domésticos como industriais. Portanto, maior também deverá ser a contribuição nos custos de despoluição dentre os municípios.

\section{Consideraçóes Finais}

Diante da necessidade de avaliar os impactos ambientais causados pelo crescimento econômico sem planejamento urbano e ambiental, evidencia-se a necessidade de buscar um equilíbrio entre atividade econômica e sustentabilidade. Isto se faz necessário devido à vulnerabilidade dos recursos naturais e a dependência destes recursos não só para a vida no planeta, mas para a própria atividade produtiva. Sendo assim, este trabalho buscou indicar uma possível solução para reduzir os impactos ambientais em dois importantes corpos hídricos do Estado de Pernambuco: a Bacia Hidrográfica do Rio Ipojuca e a Bacia Hidrográfica do Rio Capibaribe, baseado na taxação pigouviana, mais comumente conhecida como Princípio do Poluidor Pagador.

A produção de confecçóes no Agreste Pernambucano é uma das causas da poluição nas bacias hidrográficas, visto que é uma atividade extremamente poluidora e que demanda grande quantidade de recursos hídricos. Embora a poluição por efluentes industriais seja bastante significativa deve ser levado em consideração o impacto causado pelos esgotos domésticos, acentuado com o processo de urbanização. A análise realizada a partir dos dados das Bacias Hidrográficas dos Rios Ipojuca e Capibaribe verificou que a dinâmica demográfica dos municípios é o fator que mais influi na poluição dos rios. Contudo, a exceção observada no Município de Ipojuca aponta que políticas públicas de proteção ao meio ambiente são eficazes na redução dos danos ambientais.

Para a eficácia de projetos de despoluição nas bacias hidrográficas acredita-se que a cooperação entre os municípios é fundamental, haja vista a abrangência destes ambientes complexos e difíceis de serem geridos. Dessa forma, o método empregado pela teoria dos jogos, através do Valor de Shapley, mostra que o modelo de jogos cooperativos é uma forma justa de alocar custos em projetos que iráo beneficiar a todos os jogadores. O conceito de justiça é bem empregado quando se observa que, no caso analisado, quem polui mais irá arcar com custos maiores.

Diante dos resultados apresentados, vale a reflexão: os municípios que estão inseridos no Polo de Confecçóes do Agreste teriam os custos de despoluição aumentados devido 
à característica poluente deste setor econômico, independentemente do tamanho da população? A presença das indústrias de confecção é responsável por maiores danos às bacias hidrográficas em que são despejados os efluentes industriais? Este trabalho indica que não, mas faz-se necessária uma análise mais aprofundada de outros fatores para uma conclusão definitiva sobre o assunto.

Afinal, o resultado deste exercício é intrigante, especialmente para lugares com maior efetivo de lavanderias de jeans, caso do Município de Toritama. Por outro lado, talvez a informalidade e quantidade de facçóes na Região do Agreste (pequenos fabricos realizados em casa) possa explicar melhor este resultado. Inclusive porque o segundo Polo de Confecçóes do Estado é a Região Metropolitana do Recife e este apresenta-se como grande contribuidor em projetos de despoluição, ainda que coincidentemente tenha uma grande população.

Por fim, o exercício realizado aqui considera poucos elementos para análise. Quiçá em pesquisas futuras seja possível o desenho de um jogo mais complexo, com outros elementos que possam demonstrar resultados mais compreensíveis ou aceitáveis e consigam, assim, nortear melhor o poder público na elaboração de políticas públicas mais eficazes para auxiliar na conservação do meio ambiente.

\section{Referências}

AGÊNCIA CONDEPE/FIDEM. Rio Ipojuca. Recife: 2005. (Série Bacias Hidrográficas de Pernambuco, 1.). Disponível em: <http://www.condepefidem.pe.gov.br/c/document_ library/get_file?p_1_id=78673\&folderId=141869\&name=DLFE-12005.pdf $>$. Acesso em: 30 nov. 2018.

AGENCIA ESTADUAL DO MEIO AMBIENTE/PE. Relatório de Atividade 2017. Recife: 2017. Disponível em: <http:/www.cprh.pe.gov.br/ARQUIVOS_ANEXO/ RELATORIO_ANUAL_DE_ATIVIDADES_2017_FINAL.pdf;4905;20180720.pdf>. Acesso em: 30 nov. 2018.

APRILE, Fabio; PARENTE, Antonio Helder. Avaliação da qualidade das águas do Rio Ipojuca, Pernambuco - Brasil. Revista Química \& Tecnologia. UNICAP, Pernambuco, v. 1, p. 71-77. 2003. Disponível em: <https://www.researchgate.net/ publication/309034013>. Acesso em: 26 nov. 2018.

AYALA, Gustavo Alberto Amaral. Aplicaçáo de teoria de jogos à alocaçáo de capacidade firme em um sistema térmico. Dissertação (Mestrado em Engenharia Elétrica) - Pontifícia Universidade Católica do Rio de Janeiro, Rio de Janeiro, 2008. Disponível em: <https://www.maxwell.vrac.puc-rio.br/12366/12366_9.PDF> Acesso em: 30 nov. 2018.

BECKHAUSER, Sheila Patrícia Ramos; KROENKE, Adriana; HEIN, Nelson. Sustentabilidade ambiental dos países: uma avaliação com base na teoria dos jogos. In: 
XLIX Simpósio Brasileiro de Pesquisa Operacional, 2017, Blumenau. Disponível em: <http://www.sbpo2017.iltc.br/pdf/168501.pdf>. Acesso em: 26 nov. 2015.

BRAGA, B.; PORTO, M.; TUCCI, C. E. M. "Monitoramento de Quantidade e Qualidade das Águas”, in Águas Doces no Brasil: Capital Ecológico, Uso e Conservação. São Paulo, Escrituras, 2006, pp. 145-60. Disponível em: <http://www.journals.usp.br/ revusp/article/download/13529/15347> Acesso em: 30 nov. 2018.

\section{BRASIL, Agência Nacional de Águas - ANA. Conjuntura dos recursos hídricos no} Brasil 2017: relatório pleno. Brasília: ANA, 2017a. Disponível em: <http://conjuntura. ana.gov.br/static/media/conjuntura_completo.27432e70.pdf> Acesso em: 30 nov. 2018.

BRASIL, Agência Nacional de Águas. Atlas esgotos: despoluição de bacias

hidrográficas. Secretaria Nacional de Saneamento Ambiental. Brasília: ANA, 2017b.

Disponível em: <http://www3.ana.gov.br/portal/ANA/noticias/atlas-esgotos-revelamais-de-110-mil-km-de-rios-com-comprometimento-da-qualidade-da-agua-por-cargaorganica/atlaseesgotosdespoluicaodebaciashidrograficas-resumoexecutivo_livro.pdf> Acesso em: 30 nov. 2018.

BRASIL, Informe de Gestão Ambiental e Social - IGAS. Projeto de Saneamento Ambiental da Bacia do rio Ipojuca. 2012. Documento do banco interamericano de desenvolvimento. Disponível em: <http:/www.sirh.srh.pe.gov.br/site/attachments/ article/429/IGAS\%20\%20Ipojuca\%20Minuta\%2025\%20Agosto.pdf>. Acesso em: 26 nov. 2018.

BRASIL, Ministério do Meio Ambiente. Conferência das naçóes unidas sobre meio ambiente e desenvolvimento. Brasília, 2012. Disponível em: <http:/www.mma.gov.br/ informma/item/670-cap\%C3\%ADtulo-18.html> Acesso em: 30 nov. 2018.

BRASIL. Lei n. 9.433, de 8 de janeiro de 1997. Institui a Política Nacional de Recursos Hídricos, cria o Sistema Nacional de Gerenciamento de Recursos Hídricos, regulamenta o inciso XIX do art. 21 da Constituição Federal, e altera o art. $1^{\circ}$ da Lei no 8.001, de 13 de março de 1990, que modificou a Lei no 7.990, de 28 de dezembro de 1989. Diário Oficial da República Federativa do Brasil. Disponível em: <http://www.planalto.gov.br/ ccivil_03/LEIS/L9433.htm>. Acesso em: 13 nov. 2018

BRASIL, Relação Anual de Informações Sociais - RAIS. Bases Estatísticas RAIS e CAGED. Brasília, 2015. Disponível em: <http://bi.mte.gov.br/bgcaged/rais.php > Acesso em: 30 nov. 2018.

BRITO, Gil Bracarense. Gestão dos recursos hídricos: uma análise das técnicas de valoraçáo dos projetos do programa produtor de água. 2016. Disponível em: <https:// hdl.handle.net/1884/52861 >. Acesso em: 26 nov. 2018.

CÁNEPA, Eugenio Miguel; PEREIRA, Jaildo Santos. O princípio poluidor pagador: uma aplicação de tarifas incitativas múltiplas à Bacia do Rio dos Sinos no RS. Indicadores 
Econômicos FEE. Porto Alegre, v. 30, n. 2, p. 151-178, set. 2002. Disponível em: <https://revistas.fee.tche.br/index.php/indicadores/article/view/1394/1757>. Acesso em: 26 nov. 2018.

COMPAINHA DE SANEAMENTO BÁSICO DO ESTADO DE SÃO PAULO SABESP. Coleta de esgotos. São Paulo, 2018. Disponível em: <http://site.sabesp.com.br/ site/interna/Default.aspx? secaold=50>. Acesso em: 1 dec. 2018

FAUCHEUX, Sylvie e NOËL, Jean - François. Economia dos Recursos Naturais e do Meio Ambiente. 1. ed. Lisboa: Instituto Piaget, 1998.

FIANI, Ronaldo. Teoria dos Jogos: para cursos de administraçáo e economia. 2. ed. Rio de Janeiro: Elservier, 2006.

FIELD, Barry. Introdução à economia do meio ambiente. 6. ed. Porto Alegre: AMGH, 2014.

GIL, A. C. Como elaborar projetos de pesquisa. São Paulo: Editora Atlas S.A, 2002.

GUTIERREZ, Raffaela Loffredo; FERNANDES, Valdir; RAUEN, William Bonino. Princípios protetor-recebedor e poluidor-pagador como instrumentos de incentivo à redução do consumo de água residencial no município de Curitiba (PR). Eng. Sanit. Ambient. Rio de Janeiro, v. 22, n. 5, p. 899-909, 2017. Disponível em: <http://www. scielo.br/scielo.php?pid=S1413-41522017000500899\&script=sci_abstract\&tlng=pt>. Acesso em: 1 dec. 2018

INSTITUTO BRASILEIRO DE GEOGRADIA E ESTATÍSTICA - IBGE. Indicadores de Desenvolvimento Sustentável Brasil 2010. Rio de Janeiro, 2010. Disponível em: <https://biblioteca.ibge.gov.br/visualizacao/livros/liv46401.pdf>. Acesso em: 1 dec. 2018

INSTITUTO BRASILEIRO DE GEOGRADIA E ESTATÍSTICA - IBGE. Ranking IBGE Cidades. Rio de Janeiro, 2018. Disponível em: <https://cidades.ibge.gov.br/brasil/ pe/panorama>. Acesso em: 1 dec. 2018

IPOJUCA. Lei n. 1.596, de 14 de junho de 2011. Institui o Código do Meio Ambiente do Município do Ipojuca e dá outras providências.. Disponível em: <https://sogi8.sogi. com.br/Arquivo/Modulo1 13.MRID109/Registro518618/lei\%201596\%20parte\%201. pdf>. Acesso em: 13 nov. 2018

KOCHE, J. C. Fundamentos de metodologia cientifica: teoria da ciência e iniciação à pesquisa. Vozes, 2011.

LEITE, Gil Bracarense. Alocaçáo dos custos de projetos entre os usuários de água em uma bacia hidrográfica. Dissertação (Pós-Graduação em Economia Aplicada) Universidade Federal de Viçosa, Minas Gerais. 2009. Disponível em: <http://alexandria. 
cpd.ufv.br:8000/teses/economia\%20aplicada/2009/215588f.pdf >. Acesso em: 26 nov. 2018.

LEITE, Gil Bracarense. Alocação dos custos de projetos de despoluição entre os municípios da baía de Guanabara. 2016. Disponível em: <https://www.anpec.org.br/ encontro/2016/submissao/files_I/i11-1da3eb3db18b62841f87715922782ebb.pdf>. Acesso em: 26 nov. 2018.

LITTLECHILD, S. C.; OWEN, G. A Simple Expression for the Shapely Value in A Special Case. Management Science. Rio de Janeiro, v. 20, n. 3, p. 370-372, nov. 1973. Disponível em: <http://www.vcharite.univ-mrs.fr/pp/thoron/LittlechildOwen.pdf >. Acesso em: 26 nov. 2018.

LUNARDI, James; RABAIOLLI, Joel Albino. Valorização e preservação dos recursos hidrícos na busca pelo desenvolvimento rural sustentável. Revista OKARA: Geografia em debate. João Pessoa, v. 7, n. 1, p. 44-62. 2013. Disponível em: <http://www.periodicos. ufpb.br/ojs/index.php/okara/article/view/15094>. Acesso em: 26 nov. 2018.

MACEDO, Zilton Luiz. Os limites da economia na gestão ambiental. Revista Margem. São Paulo, n. 15, p. 203-222, jun. 2002. Disponível em: <http://cursa.ihmc.us/rid=1 188902425182_262941224_8695/EconomiaeGest\%C3\%A3oAmbiental-Zilton\%20 Macedo-2002.pdf>. Acesso em: 26 nov. 2018.

MARTINE, George; ALVES, José Eustáquio Diniz. Economia, sociedade e meio ambiente no século 21: tripé ou trilema da sustentabilidade?. Rev. bras. estud. popul., São Paulo , v. 32, n. 3, p. 433-460, 2015. Disponível em: <http://www.scielo.br/scielo. php?pid=S0102-30982015000300433\&script=sci_abstract\&tlng=pt>. Acesso em: 26 nov. 2018.

MORAES, Danielle Serra de Lima; JORDÃO, Berenice Quinzani. Degradação de recursos hídricos e seus efeitos sobre a saúde humana. Rev. Saúde Pública, São Paulo, v. 36, n. 3, p. 370-374, June 2002. Disponível em: <http://www.scielo.br/scielo. php?script=sci_arttext\&pid=S0034-89102002000300018\&lng=en\&nrm=iso >. Acesso em: 1 dec. 2018.

MOTTA, Ronaldo Seroa. Manual para a valoraçáo econômica de recursos ambientais. Rio de Janeiro, 1997. Disponível em: <http://www.terrabrasilis.org.br/ecotecadigital/pdf/ manual-para-valoracao-economica-de-recursos-ambientais.pdf>. Acesso em: 26 nov. 2018.

NOVAES, Ana Dolores; ROSENBLATT, David. A note on regional voting power and budget allocation in the Brazilian Congress. Revista Brasileira de Economia. Rio de Janeiro, v. 2, n. 45, p. 313-325, abr./jun. 1991. Disponível em: <http://bibliotecadigital. fgv.br/ojs/index.php/rbe/article/view/517>. Acesso em: 26 nov. 2018.

OLIVEIRA, Roberto Veras. O pólo de confecçóes do agreste de Pernambuco: ensaiando uma perspectiva de abordagem. 2012. Disponível em: <https://anpocs.com/ 
index.php/papers-35-encontro/gt-29/gt36-5/1250-o-polo-de-confeccoes-do-agreste-depernambuco-ensaiando-uma-perspectiva-de-abordagem/file>. Acesso em: 29 nov. 2018.

OSBORNE, Martin e RUBINSTEIN, Ariel. A Course in Game Theory. Boston: MIT Press, 1994. Disponível em: <http://ebour.com.ar/pdfs/A\%20Course\%20in\%20 Game\%20Theory.pdf $>$. Acesso em: 30 nov. 2018.

PINDYCK, Roberto S.; RUBINFELD, Daniel L. Microeconomia. 8. ed. São Paulo: Pearson Education do Brasil, 2013.

RIBEIRO, Vitor Filincowsky. Decisáo colaborativa com utilizaçáo de Teoria dos Jogos para o sequenciamento de partidas em aeroportos. Dissertação (Mestrado) - Universidade de Brasília, Brasília, 2013. Disponível em: <http://repositorio.unb.br/ bitstream/10482/13661/1/2013_VitorFilincowskyRibeiro.pdf>. Acesso em: 27 nov. 2018 RELAÇÃO ANUAL DE INFORMAÇÓES SOCIAIS - RAIS. Portal do ministério do trabalho. 2015. Disponível em: <http://trabalho.gov.br/rais>. Acesso em: 27 nov. 2018

SALGUEIRO, Edilayne Meneses. Alocaçáo de recursos com justiça: uma aplicaçáo de jogos cooperativos em redes de computadores. 2009. Tese (Doutorado) - Universidade Federal de Pernambuco. CIN. Ciência da Computação, 2009. Disponível em: <https:// repositorio.ufpe.br/handle/123456789/1387> Acesso em: 30 nov. 2018.

SANTOS, Ricardo Boaventura. Relaçóes entre meio ambiente e ciência econômica: reflexóes sobre economia ambiental e a sustentabilidade. Universidade Federal do Paraná, 2016. Disponível em: <https://www.maxwell.vrac.puc-rio.br/12366/12366_9. $\mathrm{PDF}>$ Acesso em: 30 nov. 2018.

SEBRAE. Estudo econômico do arranjo produtivo local de confecçóes do agreste pernambucano, 2012. 2013. Disponível em: < http://www.sebrae.com.br/Sebrae/ Portal\%20Sebrae/Anexos/Estudo\%20Economico\%20do\%20APL\%20de\%20 Confeccoes\%20do\%20Agreste\%20-\%20\%2007\%20de\%20MAIO\%202013\%20\%20 docx.pdf>. Acesso em: 26 nov. 2018.

SECRETARIA DE RECURSOS HIDRICOS - SRH. Plano hidroambiental da bacia hidrográfica do rio Capibaribe: Tomo I - diagnóstico hidroambiental volume 01/03 / Projetos Técnicos. Recife, 2010. Disponível em: <http://www.apac.pe.gov.br/down/ PHA_Capibaribe_TOMO_I_VOL_1_Diagnostico_21.07.11.pdf>. Acesso em: 30 nov. 2018.

SECRETARIA DE RECURSOS HIDRICOS - SRH. Plano hidroambiental da bacia hidrográfica do rio Capibaribe: Tomo II - cenários tendenciais e sustentáveis. Recife, 2010b. Disponível em: $<$ http://www.apac.pe.gov.br/down/PHA_Capibaribe_TOMO_II_ Cenarios_21.07.11.pdf>. Acesso em: 30 nov. 2018. 
SECRETARIA DE RECURSOS HIDRICOS E ENERGETICOS - SRHE.

Apresentaçáo do PHA da Bacia Hidrográfica do Rio Ipojuca. Recife, 2018a.

Disponível em: <http://www.sirh.srh.pe.gov.br/hidroambiental/bacia_ipojuca/index.php/ abertura>. Acesso em: 30 nov. 2018.

SECRETARIA DE RECURSOS HIDRICOS E ENERGETICOS - SRHE.

Apresentação do PHA da Bacia Hidrográfica do Rio Capibaribe. Recife, 2018b.

Disponível em: <http://www.sirh.srh.pe.gov.br/hidroambiental/bacia_capibaribe/index. php/abertura>. Acesso em: 30 nov. 2018.

SERRANO, Roberto. Cooperative games: Core and shapley value, Working Paper. 2007. Brown University, Department of Economics, Providence, RI. Disponível em: <https://www.econstor.eu/bitstream/10419/80201/1/541598503.pdf>. Acesso em: 26 nov. 2018.

SILVA, Carlos Henrique R. Tomé. Boletim do legislativo no 23, de 2012: Recursos Hídricos e Desenvolvimento Sustentável no Brasil. 2012. Disponível em: <http:// www2.senado.leg.br/bdsf/bitstream/handle/id/242667/Boletim2012.23.pdf?sequence=1> Acesso em: 30 nov. 2018

SILVA, Marcus Vinicius Amaral; SILVA, Aline Lira; BRITO, Danyella Juliana Martin; BRANCO, Danyelle Karine Santos; FERREIRA, Monaliza de Oliveira. A questão ambiental no pólo de confecçóes de caruaru: um primeiro ensaio à luz dos instrumentos econômicos de proteção ambiental. Estudos do CEPE, Santa Cruz do Sul, p. 108-132, set. 2012. ISSN 1982-6729. Disponível em: <https://online.unisc.br/seer/index.php/ cepe/article/view/2389>. Acesso em: 15 dez. 2018

SPERLING, Marcos. Introduçáo à qualidade das águas e ao tratamento de esgotos. 3. ed. Belo Horizonte: Departamento de Engenharia Sanitária e Ambiental; Universidade Federal de Minas Gerais; 2005.

THOMAS, Janet M.; CALLAN, Scott J. Economia Ambiental: Fundamentos, Políticas e Aplicaçóes. São Paulo: Cengage Learning, 2010.

TONIOLLO, Michele; ZANCAN, Natália Piva; WÜST, Caroline. Indústria Têxtil: sustentabilidade, impactos e minimização. In: VI Congresso Brasileiro de Gestão Ambiental, 2015, Porto Alegre. Anais... Disponível em: <http://www.ibeas.org.br/ congresso/Trabalhos2015/V-029.pdf>. Acesso em: 26 nov. 2015.

VARIAN, Hal R. Microeconomia: uma abordagem moderna. 8. Ed. Rio de Janeiro: Elsevier, 2012.

VASCONCELLOS, Marco Antonio Sandoval de; GARCIA, Manuel Enriquez. Fundamentos de Economia. São Paulo: Saraiva, 1998. 